\title{
Photoelectrocatalytic oxidation of As(III) over hematite photoanodes: a sensible indicator of the presence of highly reactive surface sites
}

Davide Spanu ${ }^{\mathrm{a}}$, Vladimiro Dal Santo ${ }^{\mathrm{b}}$, Francesco Malara ${ }^{\mathrm{b}}$, Alberto Naldoni ${ }^{\mathrm{c}}$, Andrea Turolla ${ }^{\mathrm{d}}$, Manuela Antonelli ${ }^{\mathrm{d}}$, Carlo Dossi ${ }^{\mathrm{a}}$, Marco Altomare ${ }^{\mathrm{e}}$, Patrik Schmuki, ${ }^{\mathrm{e}}$ Sandro Recchia ${ }^{\mathrm{a},{ }^{*}}$

${ }^{a}$ Department of Science and High Technology, University of Insubria, Via Valleggio 11, Como 22100, Italy

${ }^{b}$ CNR- Istituto di Scienze e Tecnologie Molecolari, Via Golgi 19, Milano 20133, Italy

${ }^{c}$ Regional Centre of Advanced Technologies and Materials, Faculty of Science, Palacky University,

Slechtitelu 11, 78371 Olomouc, Czech Republic

${ }^{d}$ Politecnico di Milano, Department of Civil and Environmental Engineering - Environmental Section, Piazza Leonardo da Vinci 32, Milano 20133, Italy

${ }^{e}$ Department of Materials Science and Engineering WW4-LKO, University of Erlangen-Nuremberg, Martensstrasse 7, D-91058 Erlangen, Germany

${ }^{f}$ Chemistry Department, Faculty of Sciences, King Abdulaziz University, 80203 Jeddah, Saudi Arabia Kingdom

Corresponding Author: Sandro Recchia

E-mail: sandro.recchia@uninsubria.it

Address: Department of Science and High Technology, University of Insubria, Via Valleggio 11, Como 22100, Italy

Link to the published article:

https://www.sciencedirect.com/science/article/pii/S0013468618322199 


\begin{abstract}
Hematite-based photoanodes were used for the photoelectrocatalysed batch oxidation of As(III) in water at $\mathrm{pH} 7$ and 10. Tests were carried out at different As(III) initial concentrations, ranging from $150 \mu \mathrm{g} / \mathrm{L}$ to $30 \mathrm{mg} / \mathrm{L}$. With no pre-treatments, an initial inactive period of 40-50 minutes was always observed at the beginning of every test. This initial inactive period is completely removed by a surface modification of surface active sites induced by a pre-polarisation at $800 \mathrm{mV}$ (vs. $\mathrm{Ag} / \mathrm{AgCl}$ ).

The water splitting active sites related to the $\mathrm{Fe}(\mathrm{III})-\mathrm{Fe}(\mathrm{IV})$ redox couple were proved to be not active towards As(III) oxidation. The modifications induced by the anodic prepolarisation were deeply studied: no evidence of the formation of surface highly oxidized iron sites ( $\mathrm{Fe}(\mathrm{V})$ or $\mathrm{Fe}(\mathrm{VI})$ ) and/or of highly reactive oxygen vacant sites emerges from XPS analysis. Rather, all collected charaterisation data support the conclusion that more reactive terminal oxygen species are necessary for As(III) oxydation. The As(III) abatement reaction was modelled by two subsequent first order kinetics in $\mathrm{As}(\mathrm{III})$, independently from the initial As(III) concentration: this behavior was explained suggesting that the highly reactive sites, being formed after prepolarisation, are gradually depleted during the reaction. As this reaction was proved to be very sensitive to the presence of highly reactive iron sites, its utilization as a probe reaction to study hematite photoanodes is suggested.
\end{abstract}

\title{
Keywords
}

Arsenic, Hematite photoanode, Photooxidation, Water splitting.

\section{Highlights}

1. Hematite photoanodes catalyse the oxidation of As(III) under solar illumination.

2. Up to $90 \%$ As(III) abatements are observed within 24 hours independently from the initial As(III) concentration.

3. The proposed process is in principle environmentally sustainable, as the disposal of chemicals is almost totally absent. 
4. The proposed process is also energetically sustainable as hydrogen is produced during As(III) oxidation, yielding thus a suitable power source to drive the process itself. 


\section{Introduction}

Arsenic has long been known as a toxin and extended term exposure to inorganic arsenic, mainly through consumption of contaminated waters or eating of food prepared with contaminated waters, can lead to cancer, skin lesions and other diseases [1-3]. Since the presence of arsenic in the environment is due mostly to natural sources and, to a minor extent, to industrial wastes, its compounds can be found soil, water, air as well as in plant and animal tissues [3]. Naturally occurring arsenic in drinking water represents a major source of chronic arsenic exposure, and this is the reason why accepted limits in drinking water are as low as $10 \mu \mathrm{g} / \mathrm{L}$, according to EU regulations [4].

Given their toxicity and their abundance, arsenate ions $\left(\mathrm{AsO}_{4}{ }^{3-}, \mathrm{HAsO}_{4}{ }^{2-}, \mathrm{H}_{2} \mathrm{AsO}_{4}{ }^{-}\right)$and arsenous acid $\left(\mathrm{As}(\mathrm{OH})_{3}\right)$ are the species of major concern in the typical $\mathrm{pH}$ range of natural waters $(6.5-8.5)$. Traditional physico-chemical removal processes of arsenic include: oxidation, coagulation/filtration, adsorptive media, ion exchange and reverse osmosis [5].

The adsorption on iron oxide minerals (including amorphous iron oxide, goethite, magnetite and hematite) is one of the most used techniques and several studies about this As/iron oxides interaction were reported in the literature [6-12].

In case of removal by adsorption on iron oxide materials a preliminary oxidation of As(III) to arsenate anions is desirable since: i) As(III) species are more toxic as compared to the oxidized forms [13]; ii) $\mathrm{As}(\mathrm{III})$ is less strongly retained than $\mathrm{As}(\mathrm{V})$ by iron oxide surfaces, mainly due to its neutral charge occurring at $\mathrm{pH}$ values of natural waters $[7,14]$.

Different stoichiometric oxidants have been used to convert As(III) species to As(V), among which there are oxygen, ozone, chlorine dioxide, chlorine, dichloroamine, hydrogen peroxide, permanganate and ferrate [15]. The common drawbacks of these oxidants, such as limited efficiency, expensive reagents and disposal of potential dangerous wastes, are obviously related to the massive usage of chemicals [16].

To solve some of these drawbacks, photocatalysis was recently proposed as an alternative technique to oxidize $\mathrm{As}(\mathrm{III})$ through the use of semiconductor photocatalysts, such as $\mathrm{TiO}_{2}$ [17-20], $\mathrm{Fe}_{2} \mathrm{O}_{3} / \mathrm{TiO}_{2}$ [21] and $\mathrm{WO}_{3}$ [22]. However, these processes show low quantum efficiency due to high charge 
recombination along with drawbacks related to the disposal and regeneration of exhausted powdered photocatalysts.

In principle, all these problems may be overcome by using a photoelectrochemical (PEC) oxidation approach. The application of an external bias potential increases the band banding at the solid-liquid interface and draws the photo-generated electrons away via the external circuit, leaving surface holes available for oxidation reaction. Therefore, the probability of the rapid recombination of electron-hole pairs is largely reduced [23]. The application of a bias positive potential allows to tune the activity of the PEC system mainly shifting the energy band level of the photoactive anode with respect to the redox potentials of the investigated reactions. Moreover, in the case of photoelectrodes for pollutants abatement the issue related to disposal and regeneration of materials is alleviated thus representing a suitable technology for large scale plants. Finally, the simultaneous occurrence of PEC water splitting would allow the parallel cathodic production of suitable amounts of hydrogen, which can be efficiently used as the plant power source.

Hematite $\left(\alpha-\mathrm{Fe}_{2} \mathrm{O}_{3}\right)$-based photoelectrodes have recently attracted considerable attention in PEC water splitting reaction due to their promising properties. Hematite is an earth abundant, non-toxic, photoelectrochemically stable material with a suitable valence band position for the water oxidation [24] and a narrow bandgap (1.9-2.2 eV) [25] that allows $15.3 \%$ of theoretical solar-to-hydrogen (STH) efficiency [26], thus matching the requirements for practical applications [27].

Taking into account the PEC and the arsenic adsorption properties of $\alpha-\mathrm{Fe}_{2} \mathrm{O}_{3}$, we decided to explore the idea to test hematite for As(III) PEC oxidation, using either the reactive oxygen species (ROS) generated during water splitting or by a direct interaction between $\mathrm{As}(\mathrm{III})$ and $\alpha-\mathrm{Fe}_{2} \mathrm{O}_{3}$ surface. Although different types of $\alpha-\mathrm{Fe}_{2} \mathrm{O}_{3}$-based systems, optimised for water splitting (doped, multilayered, etc. [28] (and references contained therein), are reported in the literature, we decided to work on pure $\alpha-\mathrm{Fe}_{2} \mathrm{O}_{3} / \mathrm{FTO}$ photoanodes. This decision was taken considering that, to the best of our knowledge, $\alpha-\mathrm{Fe}_{2} \mathrm{O}_{3}$ photoanodes have never been used for this application. Therefore, this work should be regarded as a proof of concept and/or as starting point of knowledges to develop more efficient systems. To obtain high surface area pure $\alpha-\mathrm{Fe}_{2} \mathrm{O}_{3}$ photoanodes with quite good PEC properties under visible light, a modified thermal-solution method was used [29]. 
As we will show later, the catalytic performances obtained with pure hematite photoanodes are not as good as the ones reported for other systems working under a photocatalytic approach (i.e. without any polarising circuit) [17-22]. Anyway, we must underline that the aim of this work is not to optimises the PEC perfomances, but rather to study the mechanism of action of hematite-based photoanodes towards As(III) oxidation, as we think that a starting basis of knowledges is fundamental to drive the research towards improvements of catalytic performances. Interestingly, this study revealed that highly oxidised iron active sites are necessary to oxidise As(III) which, in turns, means that As(III) oxidation can also be proposed as a model reaction to detect the presence of such sites.

\section{Experimental}

\subsection{Preparation procedure of $\alpha-\mathrm{Fe}_{2} \mathrm{O}_{3}$ photoanodes}

$\mathrm{FeCl}_{3} \cdot 6 \mathrm{H}_{2} \mathrm{O}$ (Sigma-Aldrich, 97\%) and $\mathrm{NaNO}_{3}$ (Sigma-Aldrich, $\geq 99.0 \%$ ) were used as precursors in the thermal-solution deposition of $\alpha-\mathrm{Fe}_{2} \mathrm{O}_{3}$ on fluorine-doped tin oxide (FTO) coated glass substrates (Sigma-Aldrich, $7 \Omega / \mathrm{sq}$ ).

Prior to the thin $\alpha-\mathrm{Fe}_{2} \mathrm{O}_{3}$ film growth, the FTO substrates $\left(2 \times 1 \mathrm{~cm}^{2}\right)$ were cleaned by sonication with acetone, ethanol, and ultrapure water, separately for $15 \mathrm{~min}$, and then dried. The synthesis of the $\alpha-$ $\mathrm{Fe}_{2} \mathrm{O}_{3}$ layer was carried out as described in the literature [26,29]. Briefly, FTO substrates were immersed for $3 \mathrm{~h}$ at $70^{\circ} \mathrm{C}$ in a water solution of $\mathrm{FeCl}_{3} \cdot 6 \mathrm{H}_{2} \mathrm{O}(0.15 \mathrm{M})$ and $\mathrm{NaNO}_{3}(1 \mathrm{M})$, at $\mathrm{pH} 1.5$, in case adjusted with $\mathrm{HCl}$; a calcination at $550^{\circ} \mathrm{C}$ for $1 \mathrm{~h}$, followed by $20 \mathrm{~min}$ at $800{ }^{\circ} \mathrm{C}$ was then performed to obtain the crystalline worm-like $\alpha-\mathrm{Fe}_{2} \mathrm{O}_{3}$.

\subsection{Characterization techniques}

The morphology of photoelectrodes was studied with the use of a XL30 Environmental Scanning Electron Microscopy (ESEM FEG Philips) at $10 \mathrm{kV}$ under high vacuum conditions. 
The analysis of optical absorption properties was performed on a UV-Vis Thermo Scientific Evolution $220 \mathrm{UV}-\mathrm{V}$ is spectrophotometer in the region of $200-800 \mathrm{~nm}$ by transmission absorption measurements.

XPS spectra were acquired using Al X-ray source equipped on a Physical Electronics 5600 instrumentation. The XPS spectra were corrected in relation to the C1s signal. The spectra were curve-fitted using OriginPro 2018 (Originlab corporation, USA) software application.

Cyclic voltammetry $(\mathrm{CV})$, open circuit voltage (OCV) and photocurrent measurements (J-V) were carried out with a three-electrode system connected to an Amel 2551 potentiostat equipped with a silver chloride electrode $(\mathrm{Ag} / \mathrm{AgCl} / \mathrm{saturated} \mathrm{KCl})$ as reference electrode, and a Pt wire as counter electrode.

$\mathrm{CV}$ measurements reported in Figure 3 were carried out at $\mathrm{pH} 13.6(\mathrm{NaOH} 1 \mathrm{M})$ with a voltage scan speed of $0.01 \mathrm{~V} / \mathrm{s}$ in the range from $-0.7 \mathrm{~V}$ to $0.50 \mathrm{~V}$ vs. $\mathrm{Ag} / \mathrm{AgCl}$. All other experiments were carried out at $\mathrm{pH} 10.0$ or $\mathrm{pH} 7.0$, using diluted $\mathrm{NaOH}$ or a phosphate buffer, respectively (see section 2.4).

A Sun 2000 Solar Simulator (Abet Technologies, calibrated at $100 \mathrm{~mW} / \mathrm{cm}^{2}$ ) coupled to an AM $1.5 \mathrm{G}$ filter was used as the vertical light source: a totally reflecting mirror has been used to deflect the light beam in the horizontal direction to carry out the measurements in light conditions.

All measurements were performed using a $250 \mathrm{~mL}$ quartz beaker, placed over a magnetic stirrer: to obtain a good light focus and a total immersion of the electrodes it was necessary to use $135 \mathrm{~mL}$ of solution in each test.

\subsection{Arsenic determination}

A potentiostat/galvanostat $\mu$ AUTOLAB type III interfaced with the multi-mode electrode stand model $663 \mathrm{VA}$ (Metrohm) was used for the voltammetric determination of As(III).

Hydrochloric acid (Fluka, TraceSELECTultra) and ultrapure water (MilliQ $18.2 \mathrm{M} \Omega \mathrm{cm}, 3 \mathrm{ppb}$ TOC) were employed.

A standard solution of 1000 ppm As (III) was prepared by dissolving $0.1320 \mathrm{~g} \mathrm{As}_{2} \mathrm{O}_{3}$ (Carlo Erba, $99.997 \%$ purity) in $2 \mathrm{~mL}$ of $1 \mathrm{M} \mathrm{NaOH}$, subsequently acidified with $2 \mathrm{~mL}$ of concentrated ultrapure $\mathrm{HCl}$ and diluted to $100 \mathrm{~g}$ with ultrapure water. The solution stored at room temperature was stable for 
at least 4 months. A 1 ppm work solution of As (III) was prepared weekly by diluting the concentrated standard solution. A $5000 \mathrm{ppm} \mathrm{Cu}(\mathrm{II})$ solution was prepared by dissolving $0.7920 \mathrm{~g} \mathrm{CuCl}_{2} \cdot 2 \mathrm{H}_{2} \mathrm{O}$ (Sigma-Aldirch, 99.999\%) in $125 \mathrm{~g}$ of a $0.5 \% \mathrm{HCl}$ solution.

A modified cathodic stripping voltammetry (CSV) [30] was used for As(III) determination. Briefly, a $10 \mathrm{~mL}$ blank solution composed by $1 \mathrm{M} \mathrm{HCl}$ and $45 \mathrm{ppm}$ of $\mathrm{Cu}(\mathrm{II})$ was purged for 5 min with $\mathrm{N}_{2}$ : the HMDE was scanned from $-0.40 \mathrm{~V}$ to $-1.00 \mathrm{~V}$ according to the parameters reported in Table 1 . Subsequent additions of the sample and of the diluted As standard solutions were performed and after each addition four replicated scans were recorded (a purge of $15 \mathrm{~s}$ was used after each addition).

Total Arsenic concentration was determined with a Thermo Scientific ICAP Q inductively coupled plasma mass spectrometer (ICP-MS) using a He-collision cell in kinetic energy discrimination (KEDS) mode with the standard conditions indicated by the factory.

\subsection{PEC oxidation tests}

The same three-electrode PEC cell and solar simulator described in paragraph 2.2 were used to perform the As(III) photoelectro-oxidation tests. A front illumination set-up was used for all the reported tests.

Preliminary tests were carried out at $\mathrm{pH} 10.0$ (adjusting the $\mathrm{pH}$ of MilliQ water with concentrated $\mathrm{NaOH}$ ). All the other tests were conducted in $2 \mathrm{mM}$ pH 7.0 phosphate buffer solution (with a 630 $\mu \mathrm{S} / \mathrm{cm}$ conductivity) obtained by dilution of a concentrated $200 \mathrm{mM}$ phosphate buffer.

The presence of As(III) in solution was ensured by the addition of a proper amount of a diluted solution obtained from the concentrated 1000ppm As(III) solution above reported. In order to avoid the influence of $\mathrm{pH}$ and conductivity variations during additions, the diluted solution was adjusted to $\mathrm{pH} 7.0$ and to $630 \mu \mathrm{S} / \mathrm{cm}$. Every test was carried out by using a solution volume of $135 \mathrm{~mL}$.

The constant applied bias potential was chosen (after CV measurements) as the voltage which ensured high recorded photocurrents avoiding contribution from electrochemical water splitting. As the result, a $660 \mathrm{mV}$ potential (vs. $\mathrm{Ag} / \mathrm{AgCl}$ ) was used for all tests carried out at $\mathrm{pH} 10.0$, while a $800 \mathrm{mV}$ potential was used for all test at $\mathrm{pH}$ 7.0. 


\section{Results and discussion}

\subsection{Characterizations of $\alpha-\mathrm{Fe}_{2} \mathrm{O}_{3}$ photoelectrodes}

The synthesised $\alpha-\mathrm{Fe}_{2} \mathrm{O}_{3}$ photoanodes show the warm-like morphology (Figure1) typical for nanostructured films grown by the solution method [29]. The cross sectional view of the photoanode (Figure $1 b$ ) allows to distinguish the different surface layers: $\alpha-\mathrm{Fe}_{2} \mathrm{O}_{3}(\sim 250 \mathrm{~nm}), \mathrm{FTO}$, and glass.

UV-vis spectrum of synthesized $\alpha-\mathrm{Fe}_{2} \mathrm{O}_{3}$ nanostructures (Figure S1) shows that the threshold absorption is located around $600 \mathrm{~nm}$. Hematite absorption is dominated by a strong transition in the region $400-600 \mathrm{~nm}$, which is assigned to the pair excitation processes ${ }^{6} \mathrm{~A}_{1}\left({ }^{6} \mathrm{~S}\right)+{ }^{6} \mathrm{~A}_{1}\left({ }^{6} \mathrm{~S}\right)$ to ${ }^{4} \mathrm{~T}_{1}\left({ }^{4} \mathrm{G}\right)+$ ${ }^{4} \mathrm{~T}_{1}\left({ }^{4} \mathrm{G}\right)$ at $485-550 \mathrm{~nm}$, and is overlapped by the contributions of ${ }^{6} \mathrm{~A}_{1}\left({ }^{6} \mathrm{~S}\right)$ to ${ }^{4} \mathrm{E},{ }^{4} \mathrm{~A}_{1}(4 \mathrm{G})$ ligand field transitions at $430 \mathrm{~nm}$ and the ligand to metal charge transfer transition band tail [31]. The double exciton process ${ }^{6} \mathrm{~A}_{1}\left({ }^{6} \mathrm{~S}\right)+{ }^{6} \mathrm{~A}_{1}\left({ }^{6} \mathrm{~S}\right)$ to ${ }^{4} \mathrm{~T}_{1}\left({ }^{4} \mathrm{G}\right)+{ }^{4} \mathrm{~T}_{1}\left({ }^{4} \mathrm{G}\right)$ yields the strongest absorption band around $535 \mathrm{~nm}$ and it is primarily responsible for the red color of $\alpha-\mathrm{Fe}_{2} \mathrm{O}_{3}$.

The PEC characterization shows a good activity towards the water splitting reaction at $\mathrm{pH}$ 13.6, even though we used a large area photoanode $\left(2 \mathrm{~cm}^{2}\right)$, which shows an onset potential for PEC water splitting of $-0.25 \mathrm{~V}$ vs $\mathrm{Ag} / \mathrm{AgCl}$ and generates a stable photocurrent density (J) of about $100 \mu \mathrm{A} / \mathrm{cm}^{2}$ at $0.23 \mathrm{~V}$ ) (Figures $\mathrm{S} 2 \mathrm{a}$ and $\mathrm{S} 2 \mathrm{~b}$ ).

\subsection{As(III) abatement tests}

The very first PEC experiments were conducted in mild basic conditions at $\mathrm{pH} 10.0$ to favour the reaction of water splitting [32], as the formation of ROS (representing important intermediates of this reaction), may play also a significant role in As(III) oxidation.

Figure 2 displays plots of the relative As(III) residual concentration vs. reaction time using different initial As(III) concentrations: a 40-45\% As(III) abatement is observed after 450 minutes, independently from the initial concentration. These tests suggest that the abatement reaction proceeds, after an initial induction time, via a first order kinetics with respect to the As(III) concentration. The presence of an initial induction time that delays the beginning of the reaction of about 30-45 minutes 
(see the inset of Figure 2) was observed in all experiments carried out in these conditions: during this period only a slight decrease of the As(III) concentration is observed. This induction period could be ascribed to the establishment of the electrode/As(III) adsorption-desorption equilibrium [33,34]. To verify this hypothesis, and to try to avoid the initial non-reactive step, an abatement test was performed keeping in contact for $30 \mathrm{~min}$ in darkness the $\alpha-\mathrm{Fe}_{2} \mathrm{O}_{3}$ photoelectrode with the electrolyte in the presence of $\mathrm{As}(\mathrm{III})$, before polarisation and illumination. As the result, the inactive induction period is still present to the same extent: this evidence clearly indicates that the establishment of the As(III) pre-adsorption equilibrium is not the cause of the presence of the initial inactive period.

After these initial tests we moved to conditions that closely resemble natural waters-like condition, working thus with a buffered solution at $\mathrm{pH} 7.0(2 \mathrm{mM}$ phosphate buffer, $630 \mu \mathrm{S} / \mathrm{cm})$.

Green and red lines reported in Figure 3a show the trends of the As(III) concentration versus time obtained by using in every experiments a $500 \mu \mathrm{g} / \mathrm{L} \mathrm{As}$ (III) solution, with and without As(III) preadsorption, respectively. As can be seen, at $\mathrm{pH} 7.0$ the photoanode shows activities which are similar (or even better) to the ones recorded at $\mathrm{pH} 10.0$ with a $20 \%$ abatement observed after about 100 minutes. Even at pH 7.0 the initial non-active phase (either with or without a pre-adsorption step in dark condition) is still present.

It is interesting to note that these preliminary data rule out any role of ROS produced by water splitting reaction in the oxidative mechanism of As(III), as these species are quickly formed from the very beginning of the test (as evidenced by the photocurrents shown in figure $3 \mathrm{~b}$ ), i.e. during the inactive induction period.

Concerning the potential capability of $\alpha-\mathrm{Fe}_{2} \mathrm{O}_{3}$ to adsorb the $\mathrm{As}(\mathrm{V})$ species being formed, we didn't observed (as detected by ICP-MS analysis) a significant decrease of the total As concentration during PEC oxidations, both at $\mathrm{pH} 10.0$ and 7.0. This can be explained considering that the total amount of hematite deposited onto the FTO substrate is only about $850 \mu \mathrm{g}$, and that the superficial amount of $\alpha$ $\mathrm{Fe}_{2} \mathrm{O}_{3}$ available for adsorption phenomena represents only a small fraction in weight of the total deposited $\alpha-\mathrm{Fe}_{2} \mathrm{O}_{3}$. 
As a final consideration, since the As(III) oxidation performances of photoanodes at $\mathrm{pH} 7.0$ are similar (or even better) to the ones at $\mathrm{pH} 10.0$, after these preliminary experiments we decided to work only at $\mathrm{pH} 7.0$, as this condition is closer to a possible application of this process.

\subsection{On the nature of the induction period}

After having ruled out any possible influence of As(III) pre-adsorption phenomena, we decided to study if a pre-polarisation step at $800 \mathrm{mV}$ (the same potential applied during the PEC abatement) in dark condition, applied before starting the abatement of As(III), could play a beneficial effect.

Figure 3a (blue and black lines) clearly show that the initial unreactive induction period is completely deleted if such a pre-polarisation is applied. Moreover, the initial reaction rate is significantly fastened as it is possible to remove up to $40 \%$ of As(III) in the first 60 minutes.

Apparently, the presence or the absence of As(III) during the pre-polarisation step in dark conditions (compare blue and black lines of Figure 3a) does not cause relevant differences in the abatement performances of the pre-activated photoanodes. As a result, all the data reported in Figure 3a rule out any possible role of $\mathrm{As}(\mathrm{III})$ in the transformations occurring during the pre-activation step, thus suggesting that a modification of the $\alpha-\mathrm{Fe}_{2} \mathrm{O}_{3}$ surface active sites could be the main process involved. To get insights about the modifications occurring at the $\alpha-\mathrm{Fe}_{2} \mathrm{O}_{3}$ surface through the pre-polarisation step, additional experiments were carried out.

Figure 4 shows CV plots obtained for the $\alpha-\mathrm{Fe}_{2} \mathrm{O}_{3}$ photoanodes in dark conditions prior and after the $30 \mathrm{~min}$ of polarization at $800 \mathrm{mV}$. In the negative voltage region of the scan the two voltammograms show the reversible $\mathrm{Fe}(\mathrm{II}) / \mathrm{Fe}$ (III) surface redox process [35]: the photoanode after polarisation shows less pronounced $\mathrm{Fe}(\mathrm{II}) / \mathrm{Fe}(\mathrm{III})$ redox peaks, which would indicate a lower surface availability of $\mathrm{Fe}$ (III) sites belonging to this reversible redox pathway. Both CVs show a slightly visible quasireversible redox process $(\sim 120 \mathrm{mV}$ peak separation $)$ in the $300-420 \mathrm{mV}$ region: this quasi-reversible process was always observed to the same extent before and after polarisation. More interestingly, both CVs show a non-reversible (with respect to the CV time scale) reduction peak in the cathodic return scan at about $1.05 \mathrm{~V}$ vs. $\mathrm{Ag} / \mathrm{AgCl}$, which is markedly more pronounced for the pre-polarised electrode. 
We may tentatively assign the first quasi-reversible redox feature at $300-420 \mathrm{mV}$ to the $\mathrm{Fe}(\mathrm{III}) / \mathrm{Fe}$ (IV) coupled. This assignment is based on the consideration that it is now well established that PEC water splitting on hematite involves Fe(IV) sites [36-38] and that these sites must be immediately formed at the beginning of the test. Anyway, we cannot rule out mechanisms involving other iron oxidation states, as it was very recently claimed that a similar peak on hematite nanorods has to be ascribed to a $\mathrm{Fe}(\mathrm{III})-\mathrm{Fe}(\mathrm{III}) / \mathrm{Fe}(\mathrm{IV})-\mathrm{Fe}(\mathrm{V})$ transition [39]. Independently from an unambiguous assignment, it should be underlined that these sites are not active for As(III) PEC oxidation, as As(III) is not depleted during the first $30-45$ min of the reaction. The formation of the As(III) oxidation active sites must be then related to the other non-reversible signal observed in the positive voltage region. According to the literature, we were initially tempted to assign the signal at $1.05 \mathrm{~V}$ to the reduction of previously formed $\mathrm{Fe}(\mathrm{VI})$ sites, as the $800 \mathrm{mV}$ pre-polarisation potential could be sufficient to reach such an high iron oxidation state (see [39] and references contained therein). This assignment is not correct since, as we will show later, XPS data rule out the formation of $\mathrm{Fe}(\mathrm{VI})$ sites after prepolarisation. In any case, we have also to rule out that the enhanced reactivity obtained with the prepolarisation step is related to the increase of the surface hole density (as reported for water splitting [36]), as the pre-polarisation step is done in dark conditions.

With the purpose of monitoring the durability of the induced surface modifications, open circuit voltage $(\mathrm{OCV})$ values were measured at increasing times after the pre-polarization step.

As shown in Figure 5, the pre-polarisation of $\alpha-\mathrm{Fe}_{2} \mathrm{O}_{3}$ causes an increase of OCV values (both under dark and light conditions): from this point OCVs decrease very slowly reaching the original values only after about one day. These data, along with the data reported in Figure 4, clearly indicate that the modification of the electrode surface is not a fast and reversible process, with respect to the CV time scale, while it appears to be reversible for longer times. The one-day reversibility of the modifications induced by the pre-polarisation step was confirmed by three As(III) PEC oxidation tests carried out introducing an open circuit delay of $1 \mathrm{~h}, 3 \mathrm{~h}$ and $24 \mathrm{~h}$ between the pre-polarisation and the beginning of the tests (Figure 6a, b and c, respectively). As the result, after a $1 \mathrm{~h}$ delay, the observed performances are close to the ones without any delay, with about $35 \%$ As(III) removed in 70 minutes (compare Figure 6a with Figure 3a - blue and black lines). After a 3h delay (Figure 6b) an induction period 
starts to reappear and the reaction rate decreases ( 25\% As(III) removed in 180 minutes). After 24h, the behaviour of the unpolarised electrode was completely restored (compare Figure $6 \mathrm{c}$ with Figure 3a -green and red lines).

From another point of view, the strong correlation that emerges between OCV values and catalytic data, indicates that OCV can be tentatively used as a convenient tool to predict the catalysts' performances towards As(III) oxidation.

The competition between water splitting and As(III) oxidation is confirmed by the data shown in Figure 7, where it can be seen that the photocurrent (that at the beginning of the test is only due to water splitting) decreases after every $100 \mu \mathrm{g} / \mathrm{L}$ addition of As(III): these data suggest that at least a part of the active water splitting sites interacts with As(III), thus reducing the oxidation of water in favour of the slower oxidation of As(III). The data reported in Figure 7 also indicate that the photocurrent lowering caused by subsequent additions of As(III) gradually decreases, with no more photocurrent changes after $500 \mu \mathrm{g} / \mathrm{L}$ of added As(III). This evidence suggests that: i) a saturation of the active sites for As(III) oxidation is reached; ii) only a fraction of the PEC oxidation active sites are active for As(III) oxidation, as a quite high photocurrent due to water splitting is still recorded after a $500 \mu \mathrm{g} / \mathrm{L}$ As(III) addition.

Diffuse reflectance UV-Vis and ATR spectroscopies were initially employed to study the nature of the active sites formed during the pre-polarisation: no appreciable differences were observed in the spectra (not shown) recorded with both techniques prior and after polarisation. These evidences indicates that no bulk hematite changes occurs, and that modifications are only happening at the $\alpha$ $\mathrm{Fe}_{2} \mathrm{O}_{3}$ surface.

XPS characterisation was then carried out in order to better emphasise modifications eventually occurring over the hematite surface. These measurements were carried out on untreated hematite and after fixed times from polarization $(0 \mathrm{~h}, 3 \mathrm{~h}$ and $24 \mathrm{~h}$ of air exposure).

It should be noted that prior and after any XPS analysis, the stability of OCV values was checked in order to exclude the occurrence of vacuum- or X-Ray-induced surface modifications on hematite: as a matter of fact OCV values didn't change significantly during every measurement. 
In Figure S3, are reported the Fe2p signals of not treated and pre-polarised samples. The presence of $\alpha-\mathrm{Fe}_{2} \mathrm{O}_{3}$ is confirmed in all samples, with peaks at $711.2,724.9$ and $719.3 \mathrm{eV}$ corresponding to the binding energies of $\mathrm{Fe} 2 \mathrm{p}_{3 / 2}, \mathrm{Fe} 2 \mathrm{p}_{1 / 2}$ and the satellite peak of $\mathrm{Fe} 2 \mathrm{p}_{3 / 2}$, respectively [40,41]. However, none of these spectra significantly differ from each other, neither in peak intensities, nor in peak positions. Therefore, no evidences of surface modification related to an alteration of the iron oxidation state could be inferred.

A noticeable effect of the polarization on the hematite surface was instead observed on O1s signals (Figure 8). Thanks to the deconvolution of O1s peaks, 3 characteristic peaks can be identified for all the samples (any attempt to fit these signals with more or less than 3 peaks failed). The relative intensities of these signals are strongly modified by the electrochemical history of the material. Any role of phosphate adsorption on such modifications can be ruled out since no differences in P2p signals after air exposure (see Figure S4) are observed. The peak located at $529.7 \mathrm{eV}$ (Peak I) correspond to the lattice oxygen $\left(\mathrm{O}^{2-}\right)$ binding energy $[40,42,43]$ and, as reported in Figure 9, its intensity is not significantly affected by the application of a positive voltage.

Instead, a clear trend, after polarization and exposure to air, was observed for Peak II (at $531.0 \mathrm{eV}$ ) and Peak III (at $532.0 \mathrm{eV}$ ). The intensity of Peak II increases considerably right after the application of $800 \mathrm{mV}$, while Peak III becomes less intense (see Figure 9): starting from this point Peak II gradually decreases its intensity after subsequent air exposures, while Peak III becomes more intense. Although the interpretation of Peak II and Peak III is a controversial matter, it is undoubtedly clarified that signals at higher binding energies are related to less electron-rich oxygen species [42]. Among the different possible assignment of Peak II, the formation of oxygen vacancies [44,45], must be ruled out since: i) oxygen vacancies are normally formed in quite hard conditions such as annealing in oxygen deficient environments; ii) the constant relative intensity of lattice oxygen signal (Peak I) does not fit with an oxygen depletion mechanism. Considering also that the signal due to the presence of adsorbed water (or organic $\mathrm{O}$ ) on hematite surface is reported to be at $\sim 533 \mathrm{eV}[43,46]$, the strong correlation between Peak II and III can be reasonably attributed to a modification of hematite surface terminations. Therefore we are inclined to assign Peak II and Peak III to the presence of $\mathrm{O}_{2}{ }^{2-} / \mathrm{O}^{-}$and 
hydroxyl groups $(-\mathrm{OH})$ on the surface, respectively [42]. The increase of the amount of high oxidative surface species $\left(\mathrm{O}_{2}{ }^{2-} / \mathrm{O}^{-}\right)$can surely account for the enhancement in PEC oxidation performances.

The restoration to starting hematite surface states is quite slow and only after 24 hours the situation returns to be almost like in the untreated sample (Figure 9). This final evidence, together with all XPS findings so far reported, matches perfectly with OCV measurements and As(III) abatement results.

\subsection{Kinetics of As(III) oxidation}

Two abatement tests over 150 and $500 \mu \mathrm{g} / \mathrm{L}$ As(III) solutions were conducted under revised conditions, i.e. after a $30 \mathrm{~min}$ pre-polarisation at $800 \mathrm{mV}$. The processed results of these two tests are reported in Figure 10a and 10b, respectively. In both cases, the overall reaction does not fit with any univariate scheme. Rather, these data could be tentatively modelled with two different and subsequent first order kinetics in As(III) concentration (see kinetic constants - $k$ - in Table 2).

In both cases the calculated $k$ values indicate that the reaction is initially fast and becomes slower after about $45 \mathrm{~min}$.

The results would indicate the initial surface concentration of the highly oxidative reactive sites (being formed during the pre-polarisation step) are gradually depleted within the first 45 min of reaction. After this initial highly active period, a steady state is reached and the catalysts' performances are constant for the whole duration of the PEC As(III) abatement.

Finally, an As(III) PEC oxidation test using alternatively 30 minutes of darkness and 30 minutes of light has been performed. This experiment was necessary to verify that the As(III) oxidation takes place at the electrode surface. As shown in Figure 11 during every 30 minutes of dark, the oxidation of As(III) stops, meaning that the oxidation happens by the direct interaction of As(III) with the active surface and that the highly oxidised iron sites are unambiguously surface sites. 


\section{Conclusions}

In this paper we have shown that $\alpha-\mathrm{Fe}_{2} \mathrm{O}_{3}$ photoanodes are active toward the PEC oxidation of $\mathrm{As}(\mathrm{III})$. It was also shown that such an oxidation reaction happens at the electrode surface and that it is not significantly related to the presence of ROS. Although an optimisation of catalytic performances is out of the goals of this paper, the reported data are promising as modifications to the anode, like the ones reported to improve water splitting performances, may also apply to As(III) oxidation.

Even though it cannot be excluded that a photocatalytic tandem configuration could be also active toward As(III) oxidation, photoelectrocatalysis should be preferred, as the presence of a bias potential was shown to be fundamental for the formation of highly reactive sites on the $\alpha-\mathrm{Fe}_{2} \mathrm{O}_{3}$ surface. In particular, the $800 \mathrm{mV}$ pre-polarisation of photoanodes leads to the formation of modified hematite surface oxygen terminations which are able to oxidise up to $30 \%$ of the initial As(III) concentration within the first $30 \mathrm{~min}$. However, these highly reactive sites are not stable for the whole duration of As(III) abatement tests. Future work will be focused in trying to stabilise these highly reactive sites by the utilisation of dopants and/or by the utilisation of a pulsed light strategy.

It is very interesting to notice that As(III) PEC oxidation tests have shown to be highly selective for the discrimination of these high oxidative surface sites, while water splitting is not. From another point of view, this final evidence prompt us to propose the utilisation of the As(III) PEC oxidation as an additional tool to study the surface reactivity of hematite-based photoanodes.

\section{Acknowledgements}

This work was supported by the Italian Ministry of Education, University and research (MIUR) through the FIRB project [grant number RBFR13XLJ9], and from Regione Lombardia through the project "SOLAR ENERGY: technology and materials for the efficient use of solar energy" - Accordo Quadro Regione Lombardia - CNR. A.N. acknowledge the support by the Operational Programme 
Research, Development and Education - European Regional Development Fund, project no. CZ.02.1.01/0.0/0.0/15_003/0000416 of the Ministry of Education, Youth and Sports of the Czech Republic. The authors would like to acknowledge ERC (340511), DFG and the DFG cluster of excellence EAM (EXC 315) for financial support. Helga Hildebrand and Ulrike Marten-Jahns are acknowledged for valuable technical help. 


\section{References}

[1] B. Mandal, Arsenic round the world: a review, Talanta. 58 (2002) 201-235. doi:10.1016/S0039-9140(02)00268-0.

[2] C.. Jain, I. Ali, Arsenic: occurrence, toxicity and speciation techniques, Water Res. 34 (2000) 4304-4312. doi:10.1016/S0043-1354(00)00182-2.

[3] World Health Organization, Guidel. Drink. Qual. (2011).

[4] European Union (Drinking water) Regulations, <EU 122_2014.pdf〉, S.I. No. 122. (2014).

[5] D. Mohan, C.U. Pittman, Arsenic removal from water/wastewater using adsorbents-A critical review, J. Hazard. Mater. 142 (2007) 1-53. doi:10.1016/j.jhazmat.2007.01.006.

[6] S. Aredes, B. Klein, M. Pawlik, The removal of arsenic from water using natural iron oxide minerals, J. Clean. Prod. 29-30 (2012) 208-213. doi:10.1016/j.jclepro.2012.01.029.

[7] S. Dixit, J.G. Hering, Comparison of Arsenic(V) and Arsenic(III) Sorption onto Iron Oxide Minerals: Implications for Arsenic Mobility, Environ. Sci. Technol. 37 (2003) 4182-4189. doi:10.1021/es030309t.

[8] Y. Mamindy-Pajany, C. Hurel, N. Marmier, M. Roméo, Arsenic (V) adsorption from aqueous solution onto goethite, hematite, magnetite and zero-valent iron: Effects of $\mathrm{pH}$, concentration and reversibility, Desalination. 281 (2011) 93-99. doi:10.1016/j.desal.2011.07.046.

[9] S. Goldberg, C.T. Johnston, Mechanisms of Arsenic Adsorption on Amorphous Oxides Evaluated Using Macroscopic Measurements, Vibrational Spectroscopy, and Surface Complexation Modeling, J. Colloid Interface Sci. 234 (2001) 204-216. doi:10.1006/jcis.2000.7295.

[10] V. Lenoble, O. Bouras, V. Deluchat, B. Serpaud, J.-C. Bollinger, Arsenic Adsorption onto Pillared Clays and Iron Oxides, J. Colloid Interface Sci. 255 (2002) 52-58. doi:10.1006/jcis.2002.8646.

[11] R. Prucek, J. Tuček, J. Kolařík, J. Filip, Z. Marušák, V.K. Sharma, R. Zbořil, Ferrate(VI)Induced Arsenite and Arsenate Removal by In Situ Structural Incorporation into Magnetic Iron(III) Oxide Nanoparticles, Environ. Sci. Technol. 47 (2013) 130315062542003. 
doi:10.1021/es3042719.

[12] V. Chandra, J. Park, Y. Chun, J.W. Lee, I.-C. Hwang, K.S. Kim, Water-Dispersible MagnetiteReduced Graphene Oxide Composites for Arsenic Removal, ACS Nano. 4 (2010) 3979-3986. doi:10.1021/nn1008897.

[13] P.H. Masscheleyn, R.D. Delaune, W.H. Patrick, Effect of redox potential and pH on arsenic speciation and solubility in a contaminated soil, Environ. Sci. Technol. 25 (1991) 1414-1419. doi:10.1021/es00020a008.

[14] A. Jain, K.P. Raven, R.H. Loeppert, Arsenite and Arsenate Adsorption on Ferrihydrite: Surface Charge Reduction and Net OH - Release Stoichiometry, Environ. Sci. Technol. 33 (1999) 1179-1184. doi:10.1021/es980722e.

[15] V.K. Sharma, M. Sohn, Aquatic arsenic: Toxicity, speciation, transformations, and remediation, Environ. Int. 35 (2009) 743-759. doi:10.1016/j.envint.2009.01.005.

[16] G. Iervolino, V. Vaiano, L. Rizzo, G. Sarno, A. Farina, D. Sannino, Removal of arsenic from drinking water by photo-catalytic oxidation on $\mathrm{MoO} \times / \mathrm{TiO}_{2}$ and adsorption on $\gamma-\mathrm{Al}_{2} \mathrm{O}_{3}, \mathrm{~J}$. Chem. Technol. Biotechnol. 91 (2016) 88-95. doi:10.1002/jctb.4581.

[17] W. Zhou, H. Fu, K. Pan, C. Tian, Y. Qu, P. Lu, C.-C. Sun, Mesoporous TiO $2 / \alpha-\mathrm{Fe}_{2} \mathrm{O}_{3}$ : Bifunctional Composites for Effective Elimination of Arsenite Contamination through Simultaneous Photocatalytic Oxidation and Adsorption, J. Phys. Chem. C. 112 (2008) 1958419589. doi:10.1021/jp806594m.

[18] H. Lee, W. Choi, Photocatalytic Oxidation of Arsenite in $\mathrm{TiO}_{2}$ Suspension: Kinetics and Mechanisms, Environ. Sci. Technol. 36 (2002) 3872-3878. doi:10.1021/es0158197.

[19] J.I. Garza-Arévalo, I. García-Montes, M.H. Reyes, J.L. Guzmán-Mar, V. Rodríguez-González, L.H. Reyes, Fe doped $\mathrm{TiO}_{2}$ photocatalyst for the removal of $\mathrm{As}(\mathrm{III})$ under visible radiation and its potential application on the treatment of As-contaminated groundwater, Mater. Res. Bull. 73 (2016) 145-152. doi:10.1016/j.materresbull.2015.08.034.

[20] Y. Wang, J. Duan, W. Li, S. Beecham, D. Mulcahy, Aqueous arsenite removal by simultaneous ultraviolet photocatalytic oxidation-coagulation of titanium sulfate, J. Hazard. Mater. 303 (2016) 162-170. doi:10.1016/j.jhazmat.2015.10.021. 
[21] H. Su, X. Lv, Z. Zhang, J. Yu, T. Wang, Arsenic removal from water by photocatalytic functional $\mathrm{Fe}_{2} \mathrm{O}_{3}-\mathrm{TiO}_{2}$ porous ceramic, J. Porous Mater. (2017). doi:10.1007/s10934-0170362-9.

[22] J. Kim, G. Moon, S. Kim, J. Kim, Photocatalytic oxidation mechanism of arsenite on tungsten trioxide under visible light, J. Photochem. Photobiol. A Chem. 311 (2015) 35-40. doi:10.1016/j.jphotochem.2015.06.006.

[23] H. Fei, W. Leng, X. Li, X. Cheng, Y. Xu, J. Zhang, C. Cao, Photocatalytic Oxidation of Arsenite over $\mathrm{TiO}_{2}$ : Is Superoxide the Main Oxidant in Normal Air-Saturated Aqueous Solutions?, Environ. Sci. Technol. 45 (2011) 4532-4539. doi:10.1021/es200574h.

[24] K. Sivula, F. Le Formal, M. Grätzel, Solar Water Splitting: Progress Using Hematite $\left(\alpha-\mathrm{Fe}_{2} \mathrm{O}_{3}\right)$ Photoelectrodes, ChemSusChem. 4 (2011) 432-449. doi:10.1002/cssc.201000416.

[25] J.H. Kennedy, Photooxidation of Water at $\alpha-\mathrm{Fe}_{2} \mathrm{O}_{3}$ Electrodes, J. Electrochem. Soc. 125 (1978) 709. doi:10.1149/1.2131532.

[26] J.Y. Kim, G. Magesh, D.H. Youn, J.-W. Jang, J. Kubota, K. Domen, J.S. Lee, Singlecrystalline, wormlike hematite photoanodes for efficient solar water splitting, Sci. Rep. 3 (2013) 2681. doi:10.1038/srep02681.

[27] L. Fu, H. Yu, Y. Li, C. Zhang, X. Wang, Z. Shao, B. Yi, Ethylene glycol adjusted nanorod hematite film for active photoelectrochemical water splitting, Phys. Chem. Chem. Phys. 16 (2014) 4284. doi:10.1039/c3cp54240h.

[28] A.G. Tamirat, J. Rick, A.A. Dubale, W.-N. Su, B.-J. Hwang, Using hematite for photoelectrochemical water splitting: a review of current progress and challenges, Nanoscale Horiz. 1 (2016) 243-267. doi:10.1039/C5NH00098J.

[29] F. Malara, F. Fabbri, M. Marelli, A. Naldoni, Controlling the Surface Energetics and Kinetics of Hematite Photoanodes Through Few Atomic Layers of NiOx, ACS Catal. 6 (2016) 36193628. doi:10.1021/acscatal.6b00569.

[30] M.A. Ferreira, A.A. Barros, Determination of As(III) and $\operatorname{arsenic(V)}$ in natural waters by cathodic stripping voltammetry at a hanging mercury drop electrode, Anal. Chim. Acta. 459 (2002) 151-159. doi:10.1016/S0003-2670(02)00086-7. 
[31] D.A. Wheeler, G. Wang, Y. Ling, Y. Li, J.Z. Zhang, Nanostructured hematite: synthesis, characterization, charge carrier dynamics, and photoelectrochemical properties, Energy Environ. Sci. 5 (2012) 6682. doi:10.1039/c2ee00001f.

[32] L. Thulin, J. Guerra, Calculations of strain-modified anatase $\mathrm{TiO}_{2}$ band structures, Phys. Rev. B. 77 (2008) 195112. doi:10.1103/PhysRevB.77.195112.

[33] C.S. Turchi, D.F. Ollis, Photocatalytic degradation of organic water contaminants: Mechanisms involving hydroxyl radical attack, J. Catal. 122 (1990) 178-192. doi:http://dx.doi.org/10.1016/0021-9517(90)90269-P.

[34] K.S. Ochoa-Gutierrez, M.A. Mueses, Experimental and mathematical evaluation of molecular adsorption models for organic pollutants on TiO2- P25 particles, Ing. Y Compet. 16 (2014) 309-320. doi:10.25100/iyc.v16i2.

[35] C.Y. Cummings, M.J. Bonné, K.J. Edler, M. Helton, A. McKee, F. Marken, Direct reversible voltammetry and electrocatalysis with surface-stabilised $\mathrm{Fe}_{2} \mathrm{O}_{3}$ redox states, Electrochem. Commun. 10 (2008) 1773-1776. doi:10.1016/j.elecom.2008.09.018.

[36] F. Le Formal, E. Pastor, S.D. Tilley, C.A. Mesa, S.R. Pendlebury, M. Grätzel, J.R. Durrant, Rate Law Analysis of Water Oxidation on a Hematite Surface, J. Am. Chem. Soc. 137 (2015) 6629-6637. doi:10.1021/jacs.5b02576.

[37] B. Klahr, S. Gimenez, F. Fabregat-Santiago, J. Bisquert, T.W. Hamann, Electrochemical and photoelectrochemical investigation of water oxidation with hematite electrodes, Energy Environ. Sci. 5 (2012) 7626. doi:10.1039/c2ee21414h.

[38] O. Zandi, T.W. Hamann, Determination of photoelectrochemical water oxidation intermediates on haematite electrode surfaces using operando infrared spectroscopy, Nat. Chem. 8 (2016) 778-783. doi:10.1038/nchem.2557.

[39] H. Bülter, G. Denuault, S. Mátéfi-Tempfli, M. Mátéfi-Tempfli, C. Dosche, G. Wittstock, Electrochemical analysis of nanostructured iron oxides using cyclic voltammetry and scanning electrochemical microscopy, Electrochim. Acta. 222 (2016) 1326-1334. doi:10.1016/j.electacta.2016.11.108.

[40] N.S. McIntyre, D.G. Zetaruk, X-ray photoelectron spectroscopic studies of iron oxides, Anal. 
Chem. 49 (1977) 1521-1529. doi:10.1021/ac50019a016.

[41] T. Yamashita, P. Hayes, Analysis of XPS spectra of $\mathrm{Fe}^{2+}$ and $\mathrm{Fe}^{3+}$ ions in oxide materials, Appl. Surf. Sci. 254 (2008) 2441-2449. doi:10.1016/j.apsusc.2007.09.063.

[42] F. Liang, Y. Yu, W. Zhou, X. Xu, Z. Zhu, Highly defective $\mathrm{CeO}_{2}$ as a promoter for efficient and stable water oxidation, J. Mater. Chem. A. 3 (2015) 634-640. doi:10.1039/C4TA05770H.

[43] M.C. Biesinger, B.P. Payne, L.W.M. Lau, A. Gerson, R.S.C. Smart, X-ray photoelectron spectroscopic chemical state Quantification of mixed nickel metal, oxide and hydroxide systems, Surf. Interface Anal. 41 (2009) 324-332. doi:10.1002/sia.3026.

[44] X. Lu, Y. Zeng, M. Yu, T. Zhai, C. Liang, S. Xie, M.-S. Balogun, Y. Tong, Oxygen-Deficient Hematite Nanorods as High-Performance and Novel Negative Electrodes for Flexible Asymmetric Supercapacitors, Adv. Mater. $26 \quad$ (2014) 3148-3155. doi:10.1002/adma.201305851.

[45] J. Socratous, K.K. Banger, Y. Vaynzof, A. Sadhanala, A.D. Brown, A. Sepe, U. Steiner, H. Sirringhaus, Electronic Structure of Low-Temperature Solution-Processed Amorphous Metal Oxide Semiconductors for Thin-Film Transistor Applications, Adv. Funct. Mater. 25 (2015) 1873-1885. doi:10.1002/adfm.201404375.

[46] A.P. Grosvenor, B.A. Kobe, N.S. McIntyre, Studies of the oxidation of iron by water vapour using X-ray photoelectron spectroscopy and QUASES ${ }^{\mathrm{TM}}$, Surf. Sci. 572 (2004) 217-227. doi:10.1016/j.susc.2004.08.035. 


\section{Captions to figures and tables}

Figure 1. (a) Top view and (b) cross-sectional SEM images of $\alpha-\mathrm{Fe}_{2} \mathrm{O}_{3} / \mathrm{FTO}$ electrode.

Figure 2. (a) As(III) concentration trends during PEC oxidation at $\mathrm{pH} 10.0$ with different starting As concentrations: $0.5 \mathrm{mg} / \mathrm{L}$ (red), $2 \mathrm{mg} / \mathrm{L}$ (green), $30 \mathrm{mg} / \mathrm{L}$ (blue). Inset: initial part of the test over the $0.5 \mathrm{mg} / \mathrm{L}$ As(III) solution.

Figure 3. (a) PEC oxidation tests over $500 \mu \mathrm{g} \mathrm{L} \mathrm{L}^{-1}$ of $\mathrm{As}(\mathrm{III})$ at $\mathrm{pH} 7.0$ with different pre-test treatments: red line -without pretreatment; green line -with 30 minutes As(III) pre-adsorption in opencircuit conditions; blue line -with the application of a $800 \mathrm{mV}$ potential (vs. $\mathrm{Ag} / \mathrm{AgCl}$ ) in dark for 30 minutes in the presence of $500 \mu \mathrm{g} \mathrm{L}^{-1}$ of $\mathrm{As}(\mathrm{III})$; black line -with the application of a $800 \mathrm{mV}$ potential (vs. $\mathrm{Ag} / \mathrm{AgCl}$ ) in dark for 30 minutes in the absence of $\mathrm{As}(\mathrm{III})$. (b) Photocurrents recorded during the red line and the black line experiments.

Figure 4. $\mathrm{CV}$ curves recorded prior (red) and after a 30 minutes polarization at $800 \mathrm{mV}$ (black): both CVs started from OCV values in the anodic direction.

Figure 5. OCV values both in dark (black) and light (red) condition (a) before a 30 minutes polarization at $800 \mathrm{mV}$ and after $0 \mathrm{~h}, 1 \mathrm{~h}, 2 \mathrm{~h}, 3 \mathrm{~h}$ and 1 day from the end of polarization.

Figure 6. PEC As(III) oxidation tests carried out after different pre-starting conditions: (a) after 1h, (b) after $3 \mathrm{~h}$ and (c) after $24 \mathrm{~h}$ from the end of polarization at $800 \mathrm{mV}$ for 30 minutes in dark.

Figure 7. Effect of the subsequent additions of $100 \mu \mathrm{g} / \mathrm{L}$ of As(III) on the photocurrent recorded at $800 \mathrm{mV}$ at $\mathrm{pH} 7.0$ 
Figure 8. (a-d) XPS O1s deconvoluted signals of hematite (a) not treated, (b) right after polarization and after (c) 3 and (d) 24 hours from the polarization.

Figure 9. Trend of the relative intensity of Peak I, II and III after polarization (0h, 3h and $24 \mathrm{~h})$ and comparison with not treated hematite (NT)

Figure 10. Kinetic linearizations of the PEC oxidation of a $150 \mu \mathrm{g} / \mathrm{L}$ (a) and a $500 \mu \mathrm{g} / \mathrm{L}$ (b) of As(III) at $\mathrm{pH}$ 7.0.

Figure 11. Abatement test at $\mathrm{pH} 7.0$ over a $500 \mu \mathrm{g} / \mathrm{L}$ As(III) solution using alternatively 30 minutes of darkness and 30 minutes of illumination.

Table 1. CSV instrumental parameters used for the quantitative determination of As(III).

Table 2. Kinetic constants and residual As(III) concentrations determined for the PEC oxidation tests shown in Figure 10. 
Figure 1

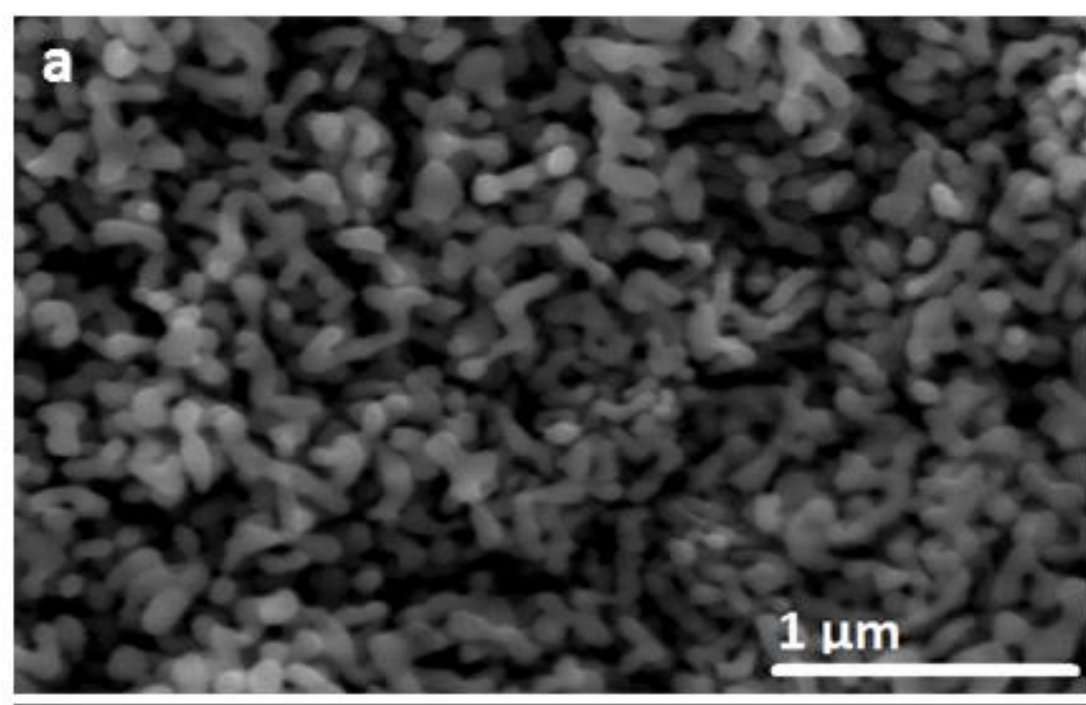

b

$$
\begin{array}{r}
\alpha-\mathrm{Fe}_{2} \mathrm{O}_{3} \\
\text { FTO }
\end{array}
$$

Glass

$1 \mathrm{\mu m}$ 
Figure 2

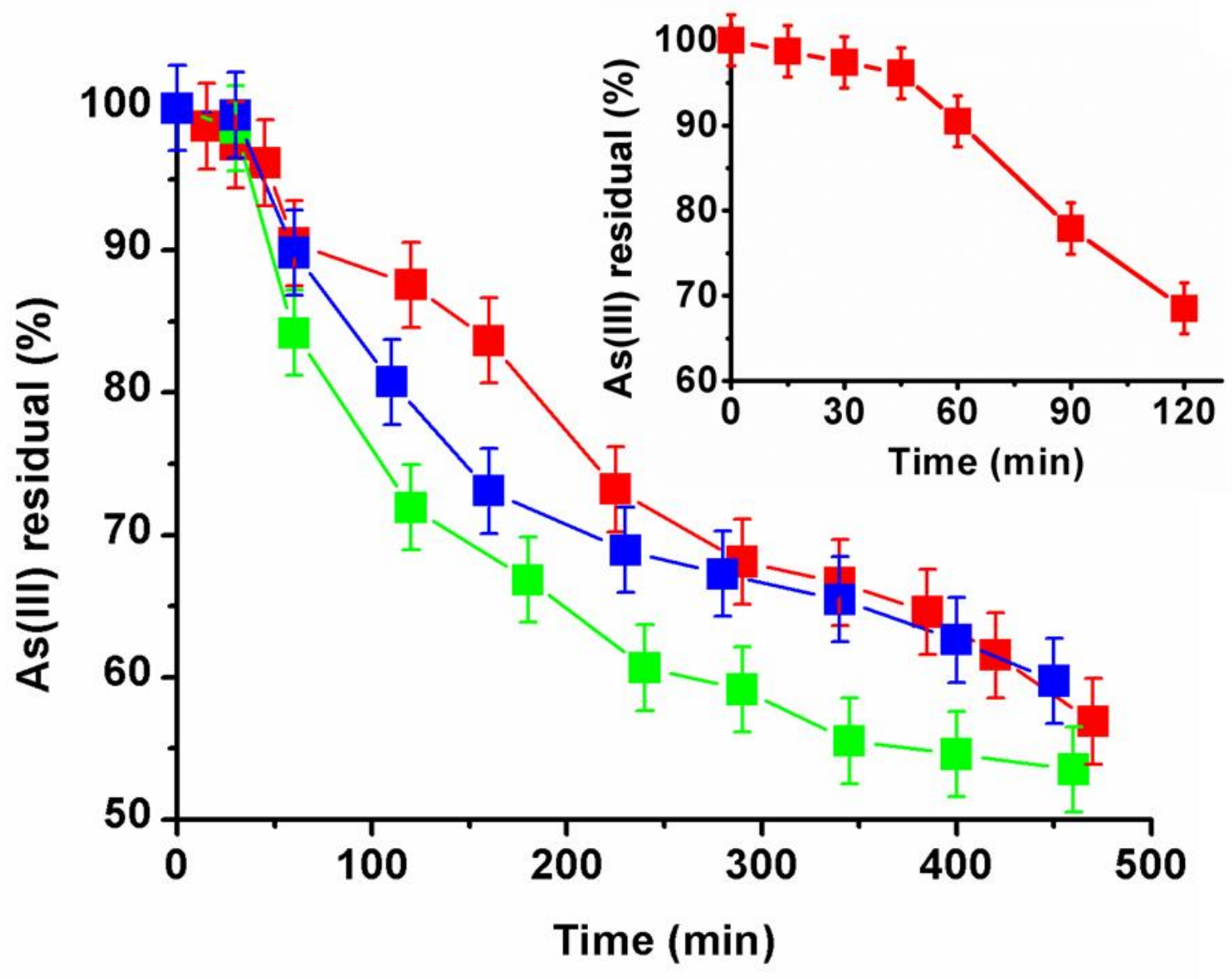


Figure 3
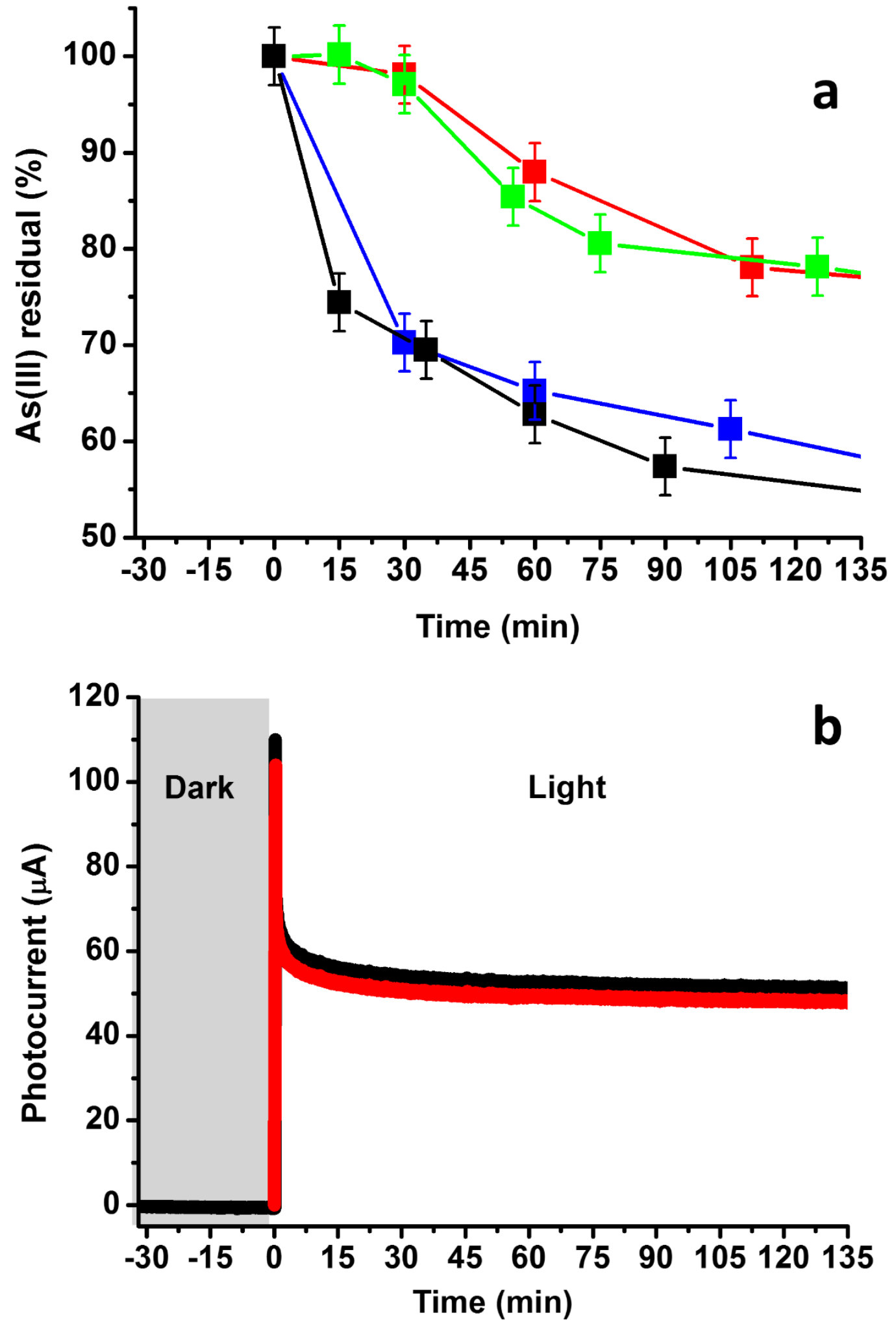
Figure 4

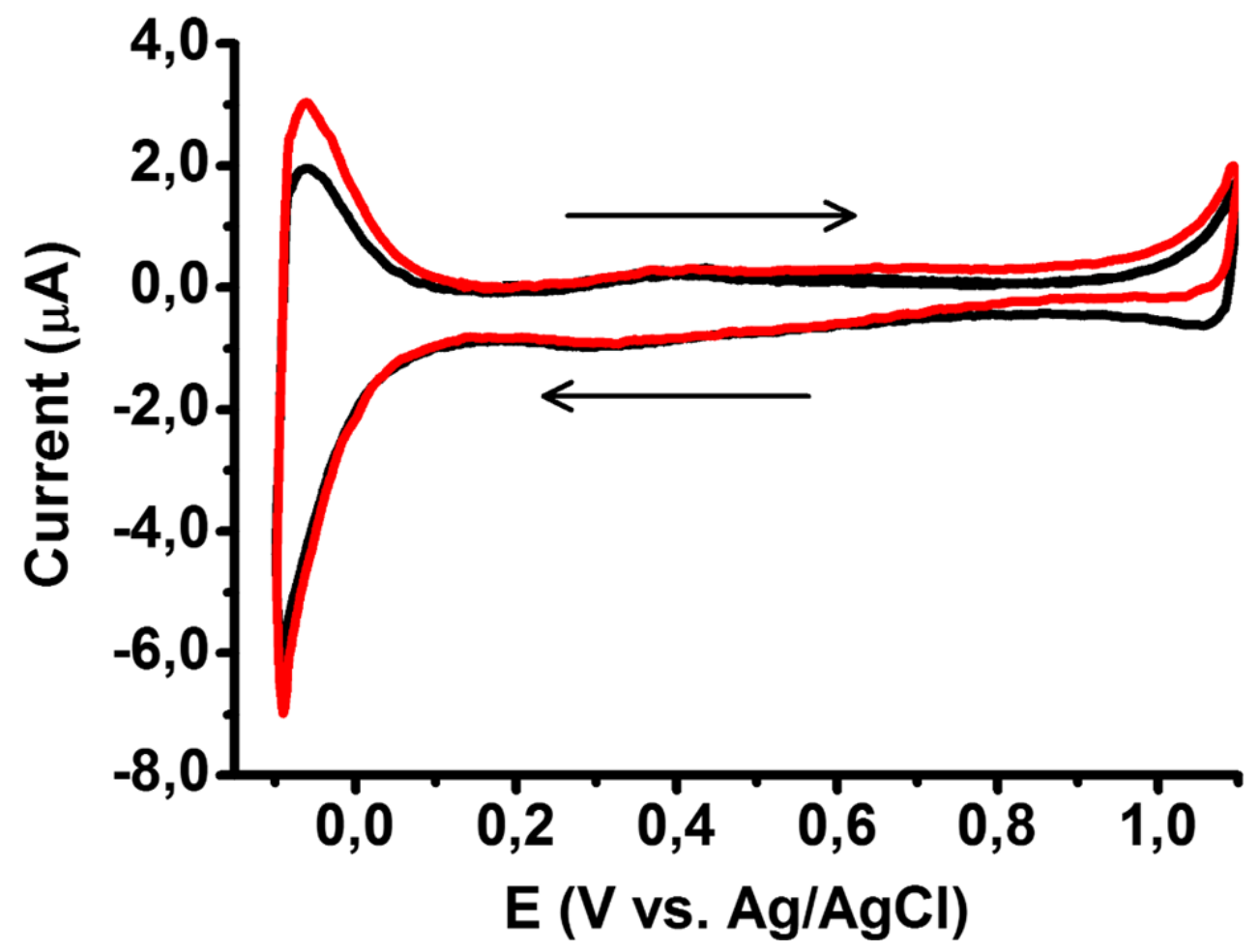


Figure 5

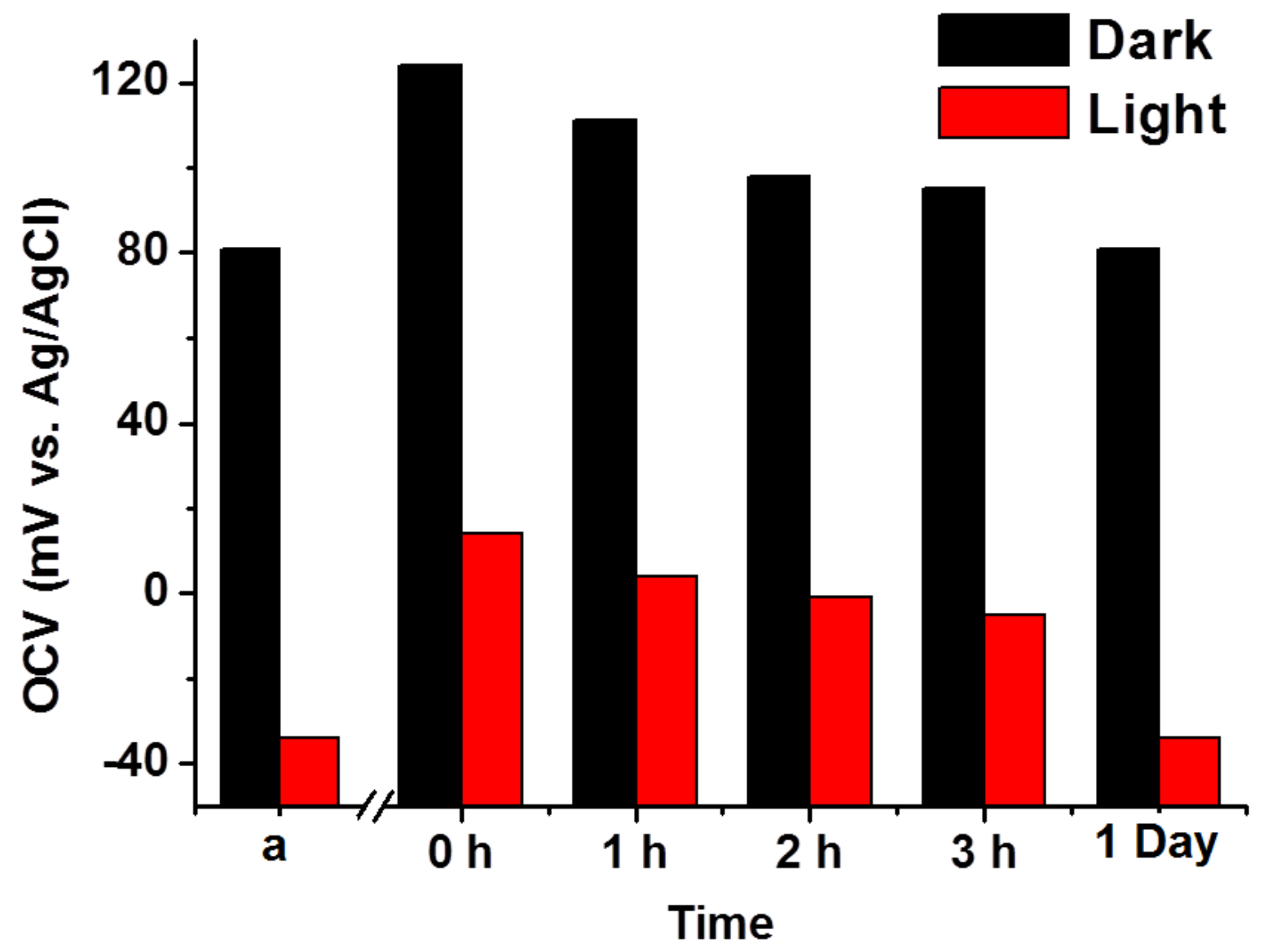


Figure 6

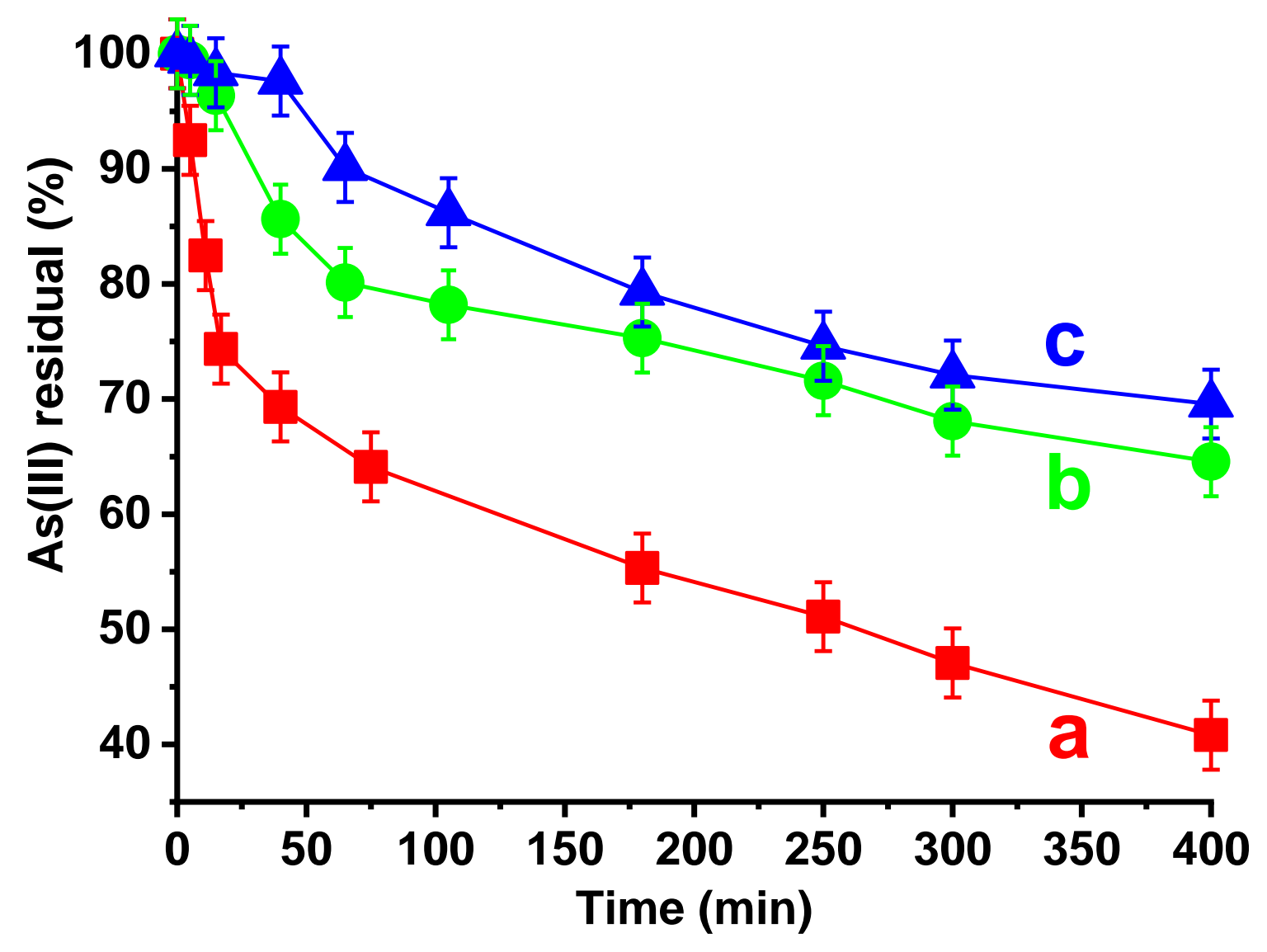


Figure 7

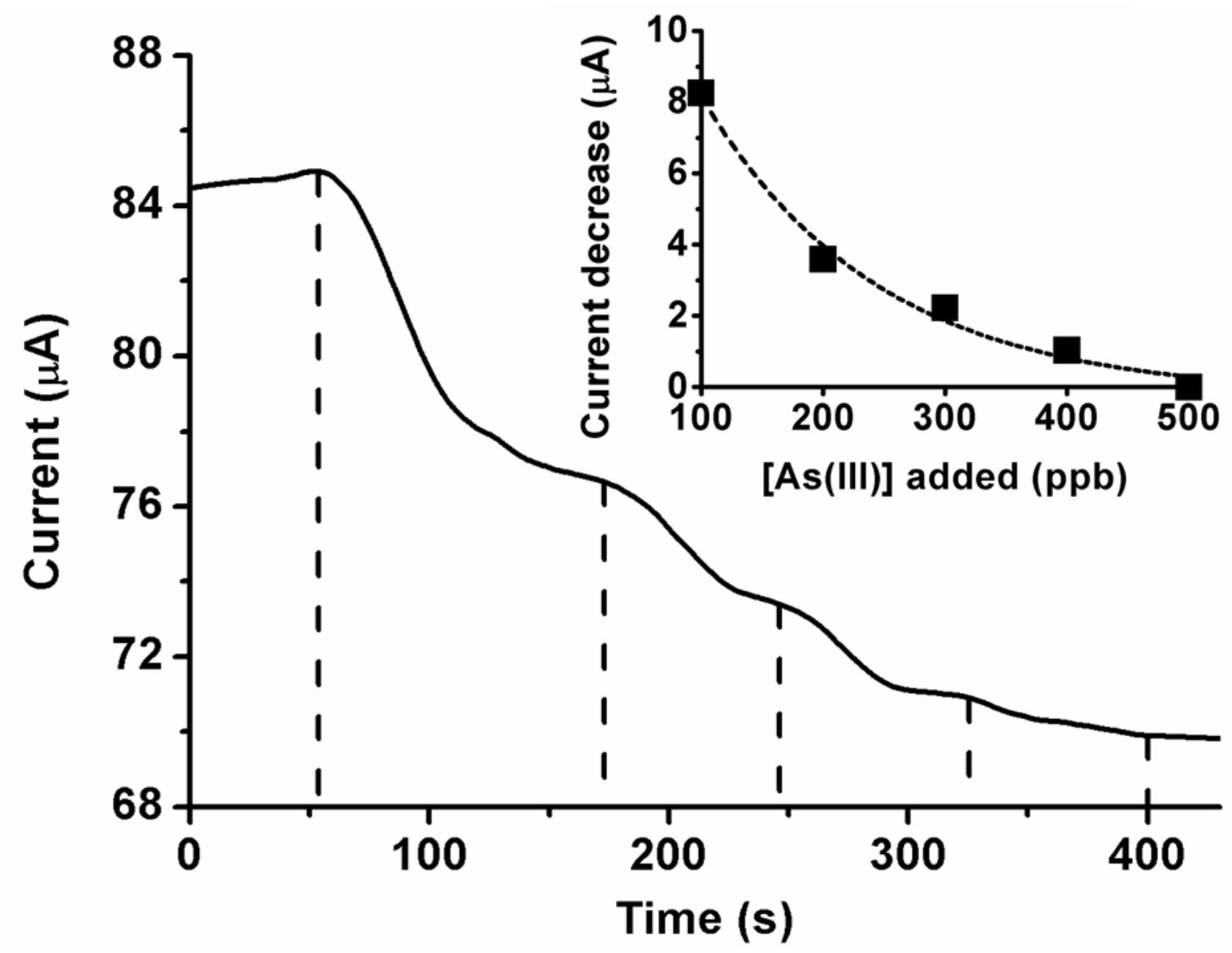


Figure 8
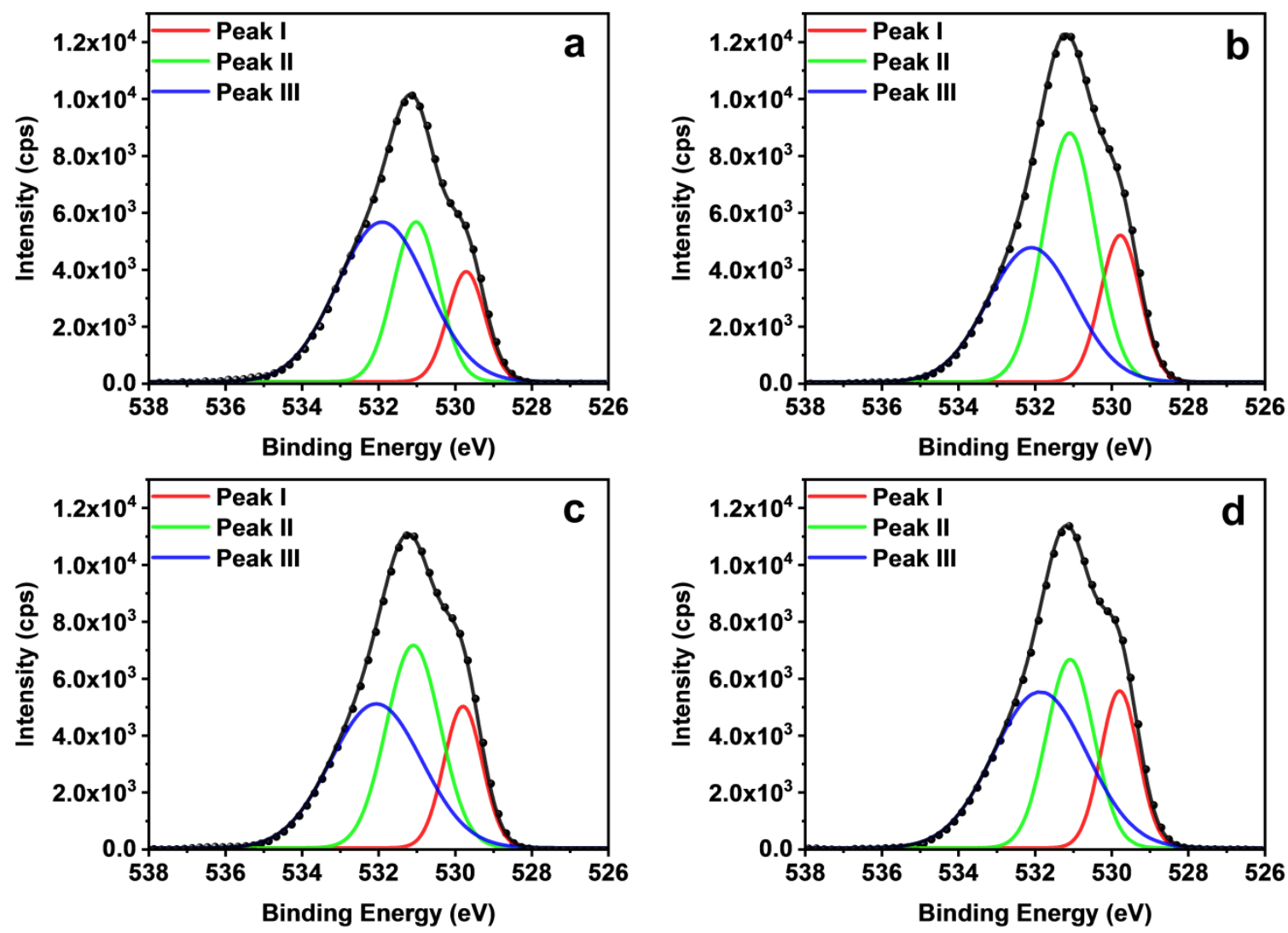
Figure 9

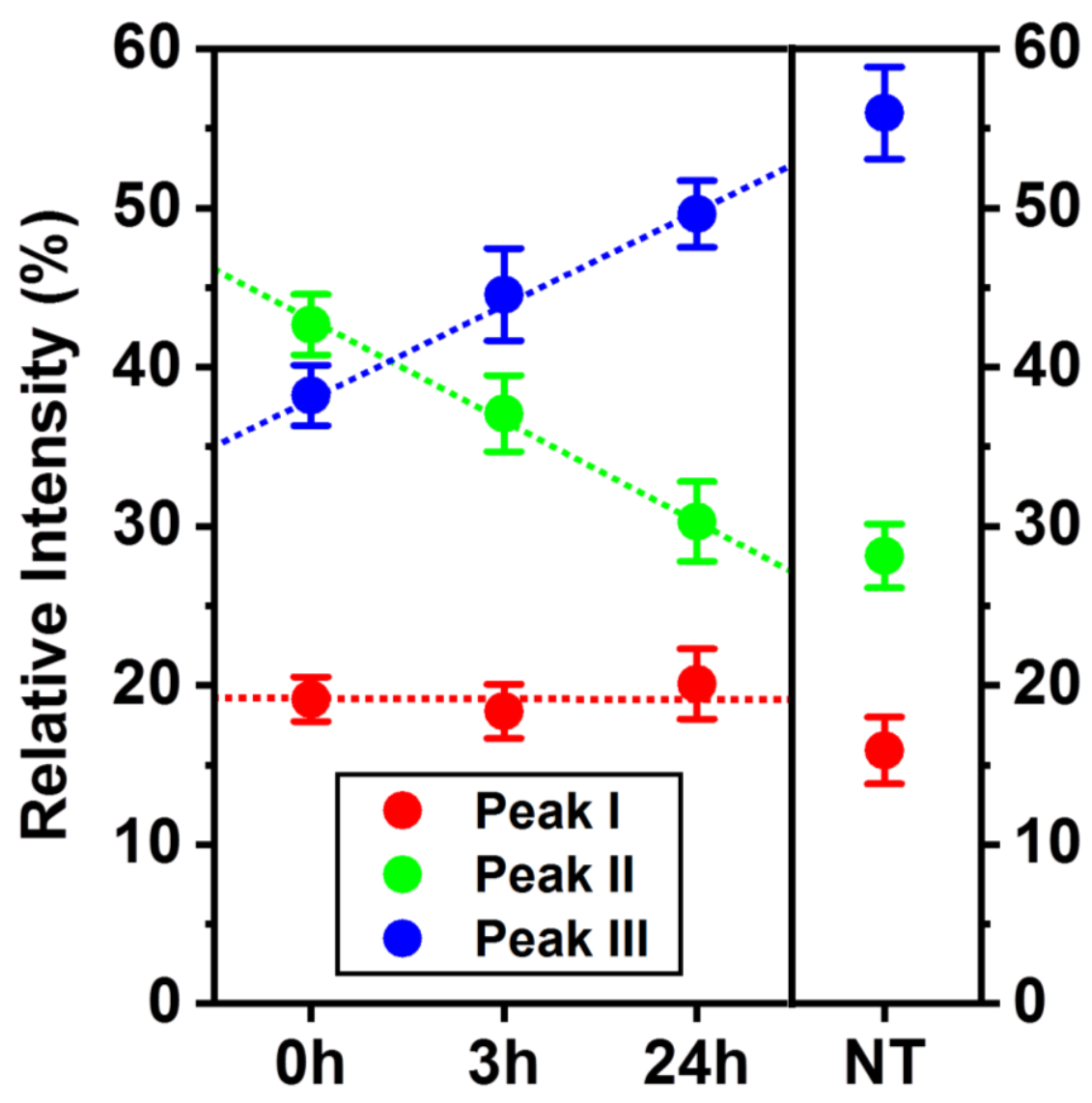


Figure 10
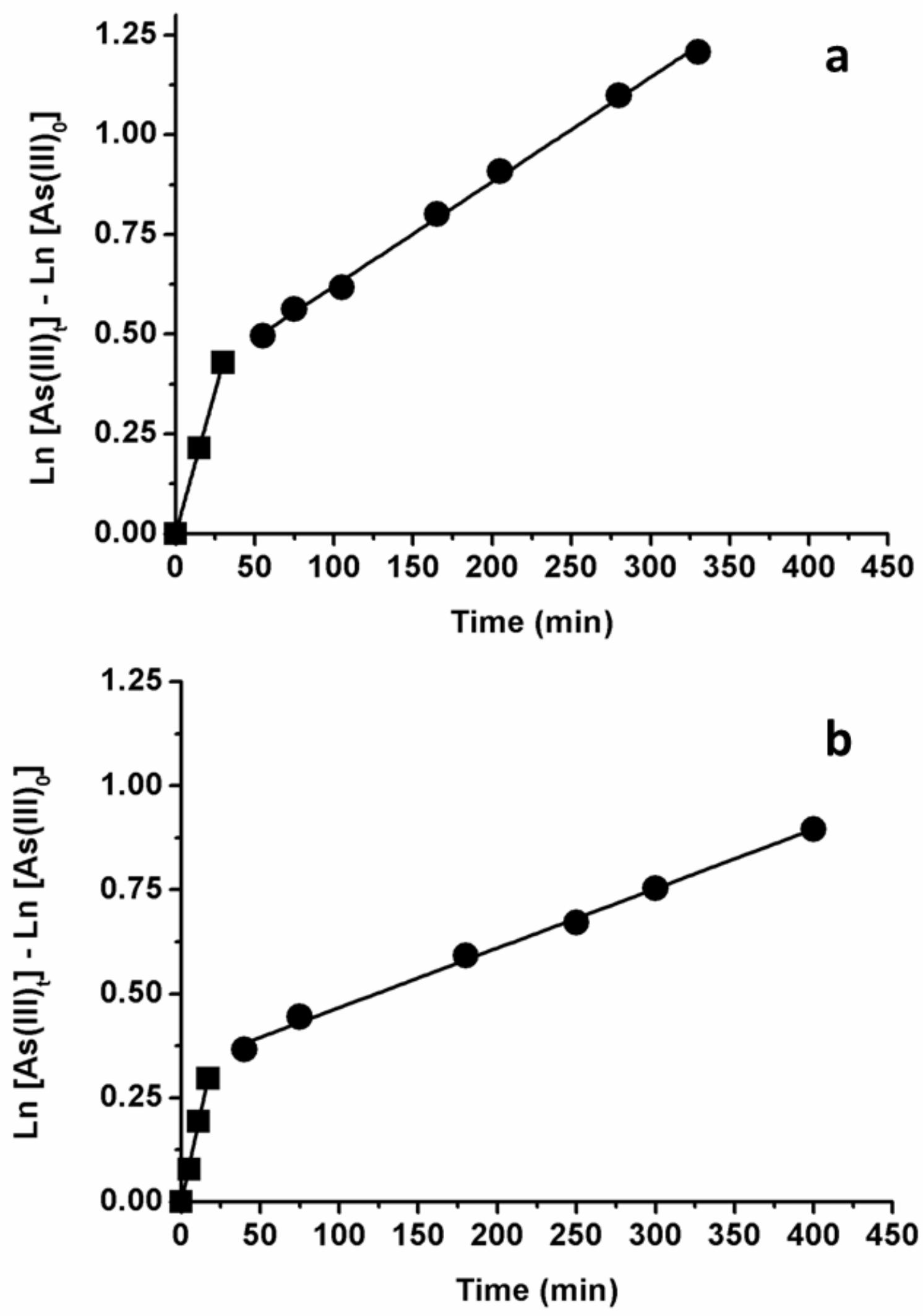
Figure 11

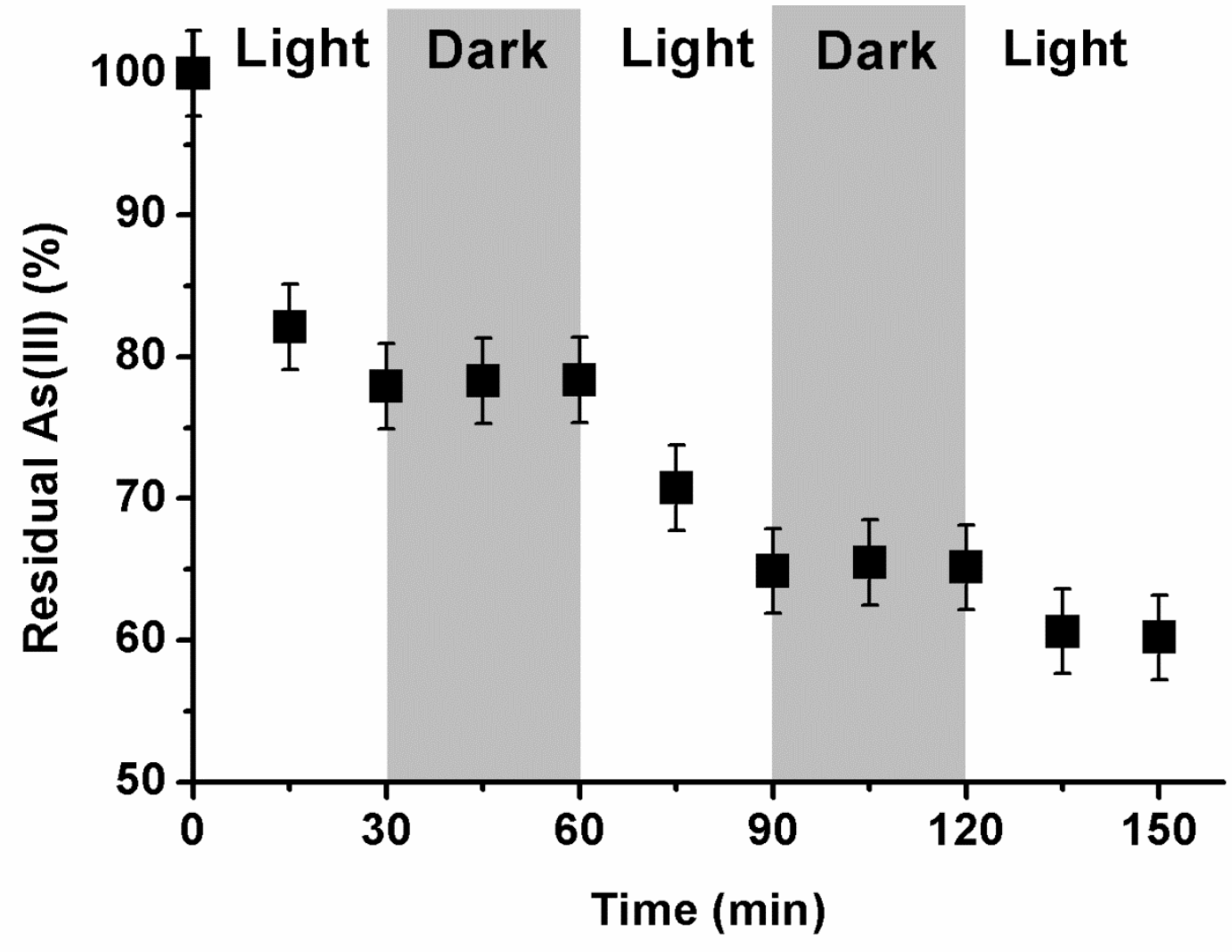


TABLE 1

\begin{tabular}{ll}
\hline Parameter & Value \\
\hline Deposition potential & $-400 \mathrm{mV}$ \\
Deposition time & $10 \mathrm{~s}$ \\
Equilibration time & $2 \mathrm{~s}$ \\
Modulation time & $60 \mathrm{~ms}$ \\
Interval time & $100 \mathrm{~ms}$ \\
Step potential & $10 \mathrm{mV}$ \\
Modulation amplitude & $80 \mathrm{mV}$ \\
\hline
\end{tabular}

TABLE 2

\begin{tabular}{llll}
\hline As (III) conc. $(\mu \mathrm{g} / \mathrm{L})$ & $\mathrm{k}_{1}\left(\mathrm{~min}^{-1}\right)$ & $\mathrm{k}_{2}\left(\mathrm{~min}^{-1}\right)$ & $\%$ residual As $(\mathrm{III})$ after $24 \mathrm{~h}$ \\
\hline 150 & 0.0143 & 0.00262 & 7.50 \\
500 & 0.0176 & 0.00143 & 17.15 \\
\hline
\end{tabular}

